\title{
Development and Implementation of Touch Screen Multimedia Technology in Sports Physiology Curriculum
}

\author{
http://dx.doi.org/10.3991/ijet.v11i01.5144 \\ Ziyi YU \\ Hubei University of Automotive Technology, Shiyan, China
}

\begin{abstract}
With the advance of technological development, many emerging technologies have been successfully applied in the teaching field, resulting in significant improvements in teaching effects. However, applying these technologies to sports specialty teaching is difficult because of certain limitations of the specialty. Few trials have been made to reform teaching methods. This study analyzes innovative studies on existing sports teaching, points out shortcomings, and attempts to introduce touch screen multimedia technology in the sports specialty. This study also discusses the theoretical basis and supporting technology to construct touch screen multimedia teaching system, as well as the design and implementation of this system. The author applies this system in Sports Physiology teaching and designs a control experiment. Results show that the practical teaching effect of touch screen computer-assisted sports is superior to the traditional teaching method, and this technology offers a new teaching mode for sports teaching.
\end{abstract}

Index Terms-multimedia, teaching, touch screen, Sports Physiology, sports specialty

\section{INTRODUCTION}

In recent years, multimedia and long-distance online education has become one of the essential means of teaching [1]. However, most courses of in the sports specialty are taught through spot demonstration or verbal teaching because of the particularity of the specialty. Such teaching methods cannot reach the expected effect. Thus, considerable innovations to the teaching mode of sports specialty should be introduced.

Zhou and Cao [2] applied multimedia computerassisted teaching in sports teaching practice, and the experiments proved showed that multimedia teaching could boost academic performance. Aiming at the shortcomings of traditional sports teaching and computer-assisted teaching system, Zhou [3] applied Internet, multimedia, and artificial intelligence to propose a brand-new intelligent teaching system. He applied this system to long-distance sports teaching practice by following the dynamic features of sports teaching to prevent time and place limitations and for teaching strategies to be adopted for individualized teaching based on student conditions. Zhao et al. [4] proposed a sports cognitive learning strategy based on computer technology and "teacher-student-multimedia" multiple-interaction learning theory, as well as designed and developed share-based sports multimedia teaching system. Several teaching materials of the system are applicable to network autonomous and collaborative learning. Other teaching materials are applicable to synchronous assisted learning of gymnasium. The system offers teaching resources that support autonomous and collaborative learning of the students. Existing research results boost the teaching effect of sports specialty to some extent, but these teaching methods often involve complex operations; special training is needed to master them and hence would not be beneficial to promotion.

Touch screen is a kind of human-machine interaction input equipment. In essence, the touch screen is a sensor that is generally composed of touch inspection component and touch screen controller. The touch inspection component is located at the front end of the displayer screen and is used to detect touch point and to transmit relevant information to the touch screen controller. In turn, the touch screen controller receives touch information, transforms it into coordinates, and sends it to CPU. The touch screen controller also receives and executes the order sent out by CPU. Touch screen technology simplifies humancomputer interaction interface and has been successfully applied in various aspects of life, including education field. Furthermore, touch screen technology has also evolved into multimedia, 3D, and large screen.

Profiting from the rapid development of touch screen technology, touch screen and multimedia have been blended into people's daily life and work and have become inseparable constituent parts. The function of "touch and get it" is preferred by most people because of the ease of operability [5]. Thus, an increasing number of researchers have introduced touch screen multimedia technology in relevant fields. Klatzky [6] proposed the application of touch and vibration stimuli to design the graph interface of touch screen and to utilize sound enhancement signal to help the blind receive external information by using touch screen and achieve the purpose of teaching for the blind. The purpose of Islam et al. [7] in presenting the new and cost-effective laser ray touch screen technology is to create a touch screen that can be operated easily by the users without training and can be portable and movable without the display system. Kim et al. [8] combined blog, applications, and touch screen technology and applied them to a chemistry course in senior high school. This teaching experiment is oriented to blogs. Applications and touch screen technology were applied to interact with students in the chemistry course. The results showed that the students in the experimental group gained interaction and individualized teaching experience, which resulted in an improvement in their learning interest.

This research designs and develops an innovative touch screen multimedia teaching software and then applies the 
system to the teaching practice of Sports Physiology to verify the effects of the system.

\section{THEORETICAL BASIS OF TOUCH-TYPE Multimedia TEACHING}

\section{A. Human factors engineering}

Human factors engineering, also called ergonomics, is a science based on psychology, physiology, anatomy, and anthropometry. This type of science studies how to make system designs comply with human body structure and physiological and psychological features to achieve the best match of human, machine, and environment and enable people under different conditions to work and live in an efficient, safe, healthy and comfortable way [9].

\section{B. Color ergonomics theory}

Color is an important display content in the multimedia making process. Color plays a great role in vividly expressing the main idea of courseware, communicating the teaching contents, attracting student attention, and providing a foil for the learning atmosphere. Thus, in the multimedia making process, having profound knowledge of the characteristics of color is necessary, as well as mastery of color formation rules and correlation and the application of visual and psychological effects of color to highlight the theme and enhance vividness to attract attention and leave a lasting impression [9].

\section{Visual psychology theory}

Visual sense is one of the most important feelings of human beings. This sense refers to human psychological mechanism reaction to external images triggered by the visual organ. Approximately $83 \%$ of information acquired by human beings comes from the visual sense. Visual psychology is a branch of psychology that studies basic physiological mechanism and basic rules of human vision. In trigger-type multimedia teaching, visual effect takes form through pictures and video demonstration. By applying such visual principles as a sense of order, visual integration, visual disorder, visual persistence, color and light, dynamic and static states, and multi-view and multidimensional learning atmosphere are created for students. In turn, the learning enthusiasm of students is boosted and visual fatigue reduced.

\section{TECHNOLOGICAL IMPLEMENTATION OF TOUCH SCREEN Multimedia TEACHING SOFTWARE}

\section{A. System functions and features}

This study designs and develops an innovative touch screen multimedia teaching software. Teachers may control multimedia teaching materials through the touch screen and perform synchronous demonstration using the projector. A schematic diagram of system application scene is shown in Figure 1.

\section{B. System design}

\section{1) System architecture design}

System architecture is shown in Figure 2, which includes the control module of touch screen, main computer module of multimedia, projector, and large screen.

\section{Structure Diagram}

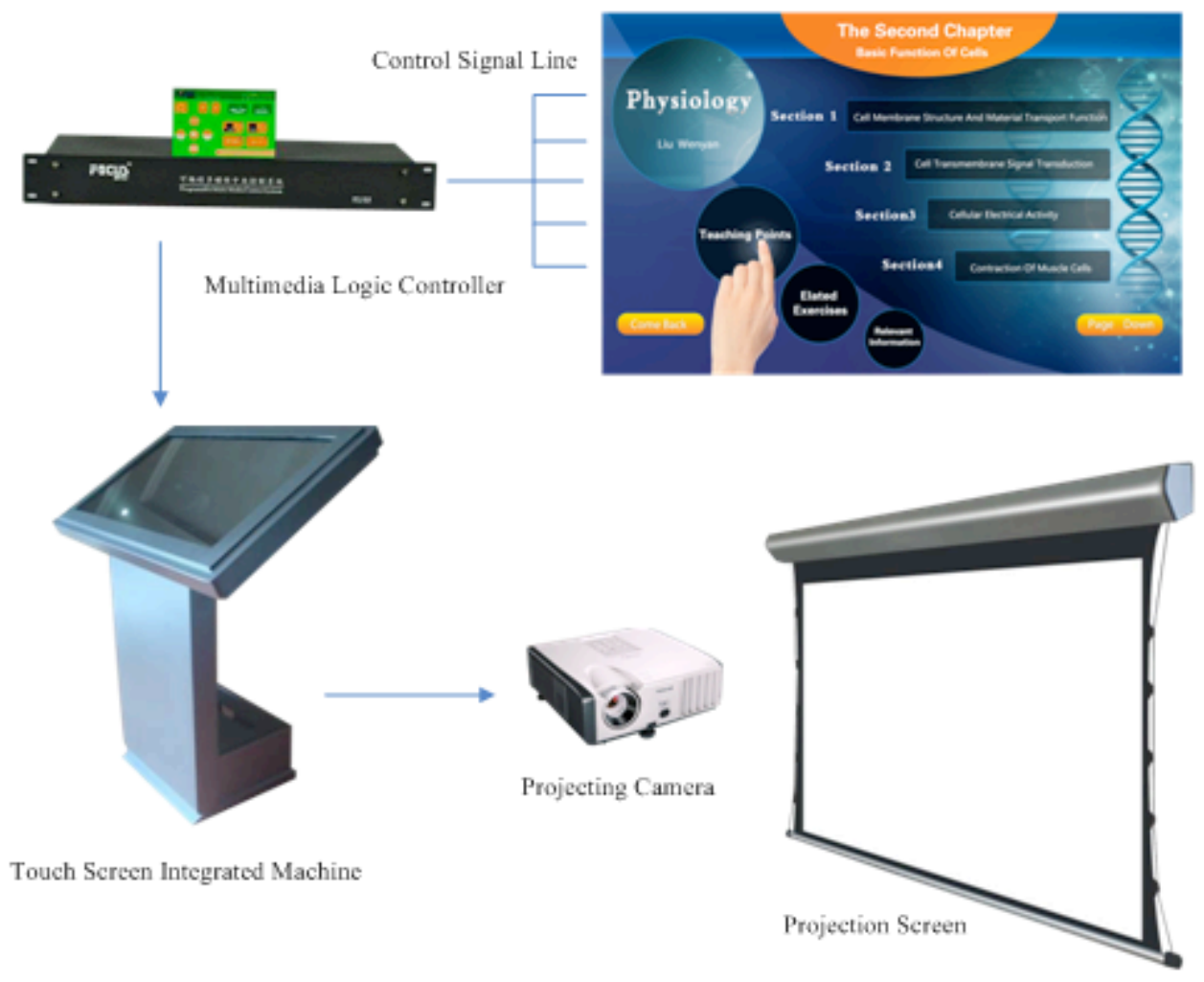

Figure 1. T Schematic diagram of system application scene 


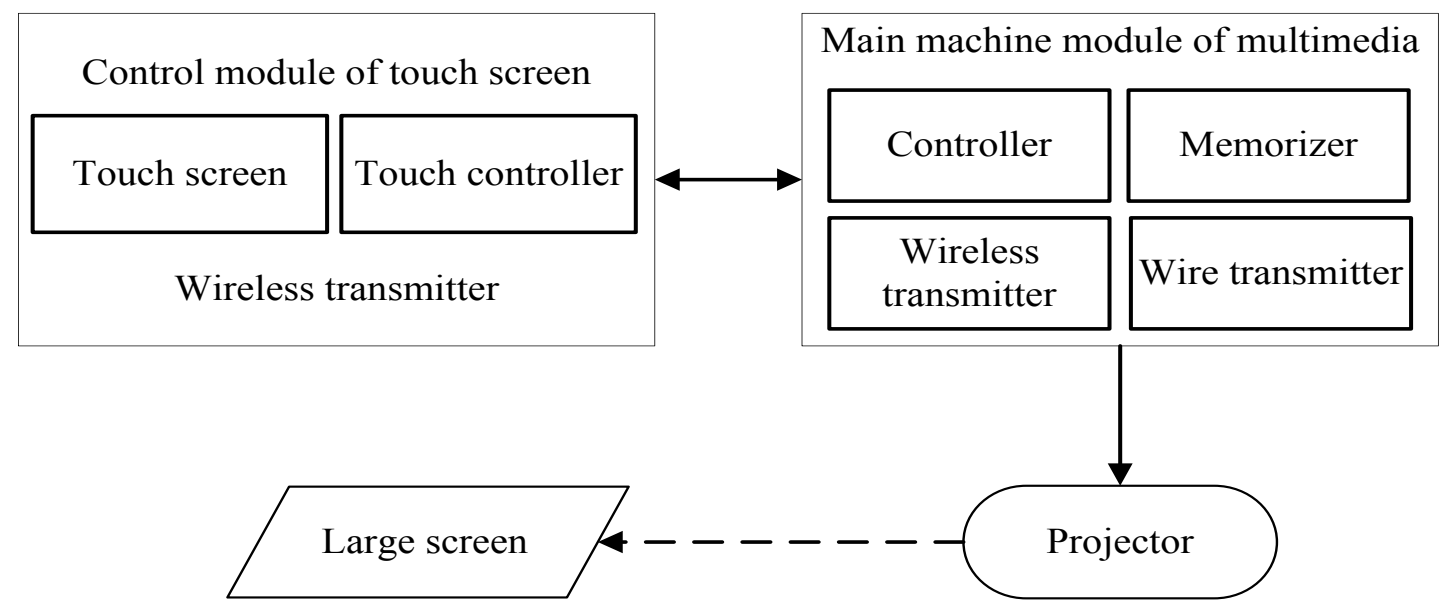

Figure 2. System architecture

First, teachers need to store multimedia teaching materials in the memorizer of the main multimedia machine. In teaching, multimedia teaching materials can be synchronized to touch screen control module (data are transmitted after compression) through wireless transmission and later synchronized to the projector through wire transmission and displayed on a large screen (data can be directly transmitted without compression). Teachers choose the control order through the touch screen and adjust the multimedia teaching materials. The main multimedia machine module receives the order from the touch screen control module through wireless transmission and adjusts the content of the teaching system display according to the order.

\section{2) System architecture design}

Teachers need to display the multimedia teaching materials through the touch screen interface control. The touch screen control order is arranged according to the teaching needs. The order includes open, enlarge, narrow, move, turn forward, turn backward, angle rotation, delete, and touch write.

Open is used to control the opening of multimedia data files or to control file play or pause. Enlarge and narrow are used to adjust the proportion of the display content. Move is used to adjust the display content position. Turn forward and turn backward are used to control page turning. Angle rotation is used to adjust the angle of relevant elements. Delete is used to delete some elements. Touch write is used to write on the touch screen.

\section{System implementation}

Programming development is performed based on the relevant system design scheme and the above key supporting technologies to achieve system functions. Figure 3 shows the homepage of the touch-type multimedia teaching software through which one may choose the corresponding chapter and check the key teaching points, exercise, and reference. Figure 4 shows a screenshot of the multimedia display interface that can be used to control and adjust the display contents.

\section{TEAChing Experiment Of TOUCH SCREeN MulTimedia TEACHING SOFTWARE}

\section{A. Experimental design}

To verify the teaching effect of the touch screen multimedia teaching software design implemented in this study, the author applies this teaching software system in sports specialty and chooses Sports Physiology as the experimental course. The author designs a control experiment for reference. In particular, three groups of students were chosen to participate in this course, with each group comprising 20 students. The first group is the traditional teaching group. Under a classroom environment, teachers teach using traditional courseware and blackboard-writing. The second group is the touch screen multimedia teaching group, where teachers taught by touch-type multimedia teaching software system. The third group is the mixed teaching group, where teachers chose either traditional or touch screen multimedia teaching method.

The author tested the three groups at the end of final semester. All students used the same set of examination items under the same classroom environment and same time. The full score is 100 . The examination results of three groups, average deviation of pairwise comparison, and $\mathrm{P}$ value are shown in Tables I and Table II.

\section{B. Experimental results}

One-way analysis of variance shows that the result difference of the three groups is statistically significant $(\mathrm{F}=24.68, \mathrm{P}<0.001)$. The LSD method is adopted for pairwise comparison. The results show that the outcome in the traditional teaching group is lower than that in the software teaching and mixed teaching groups; the difference is statistically significant $(\mathrm{P}<0.05)$. These results indicate that the teaching effect in the traditional teaching group has a large gap with the other two groups, i.e., the teaching effect in the software teaching and mixed teaching groups are superior to that in the traditional teaching group. The average deviation of the software teaching and mixed teaching groups is relatively small, but the $P$ value is less than 0.05 , indicating that the teaching effect in the mixed teaching group is superior to that in the software teaching group. 
PAPER

Development and Implementation of Touch Screen Multimedia TeChnology in Sports Physiology...

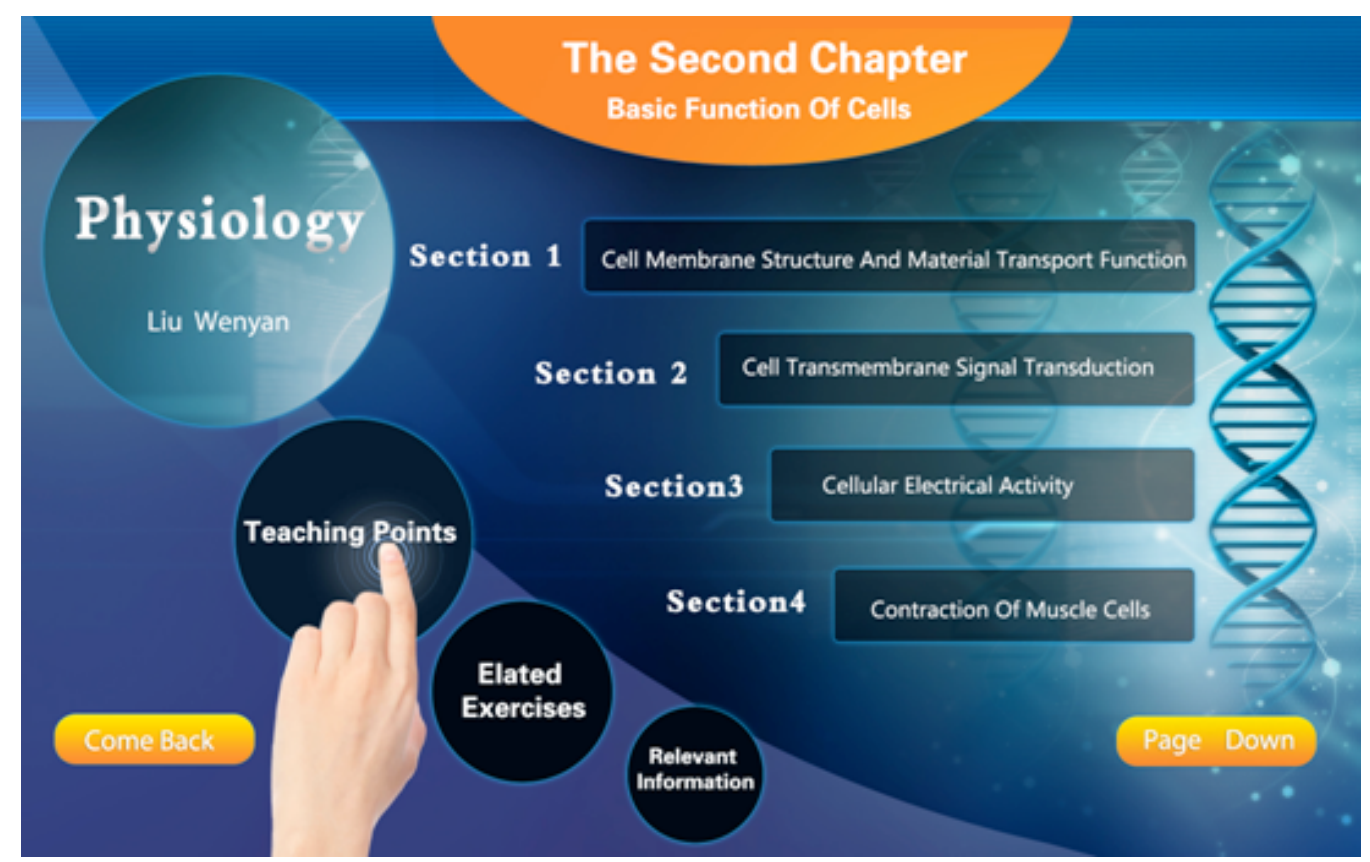

Figure 3. Homepage control interface of system

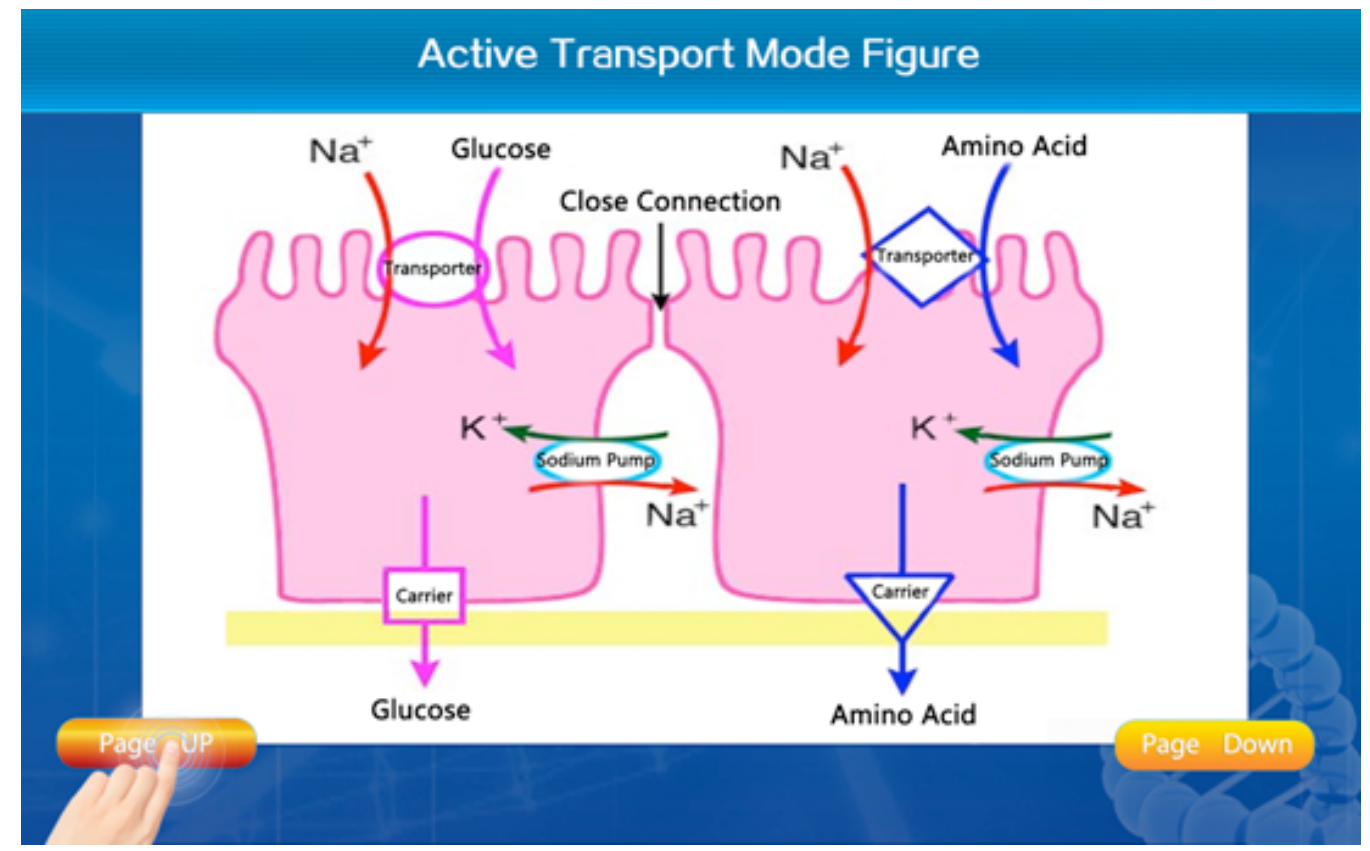

Figure 4. Screen shot of multimedia display interface

TABLE I.

STATISTICAL ANALYSIS TABLE OF EXPERIMENTAL RESULTS

\begin{tabular}{cccccc}
\hline Group & Number & Mean score & Standard deviation & Minimum score & Maximum score \\
\hline Traditional teaching group & 20 & 78.3 & 3.6 & 73 & 87 \\
Software teaching group & 20 & 84.1 & 2.9 & 79 & 88 \\
Mixed teaching group & 20 & 86.7 & 4.8 & 80 & 94 \\
\hline
\end{tabular}

TABLE II.

PAIRWISE COMPARISON RESULTS

\begin{tabular}{ccc}
\hline Group & Mean difference & P \\
\hline Software teaching group - traditional teaching group & 5.8 & $<0.001$ \\
Mixed teaching group - traditional teaching group & 8.4 & $<0.001$ \\
Mixed teaching group - software teaching group & 2.6 & 0.038 \\
\hline
\end{tabular}




\section{Analysis}

Sports Physiology course covers considerable content that include anatomical physiology, human immunology, procreation and development, and nutrition. As an abstract and profound course, students often complain of the lack of theoretical knowledge and dullness of this course in learning process. Vividly showing anatomy pictures related to body science and three-dimensional image can be very difficult under traditional teaching environments. With the help of touch screen multimedia teaching software, teachers may display vivid and rich multimedia teaching materials to students, reflect abstract and complex knowledge at different directions, levels, and space, make dull and abstract theories become more vivid, and transform the static state into the dynamic state. Moreover, this software can help fully mobilize the ability of students to acquire knowledge through multiple sense organs and boost their learning interest and participation. In this way, all kinds of students can experience the process of theory construction in person and develop their cognitive structure, autonomously construct the cognitive structure of anatomy, and eliminate boredom from learning. In the classroom setting, touch screen multimedia teaching software can stimulate the learning interest of students, boost their learning enjoyment, enhance their attention, promote student cognition, and strengthen their understanding and memory.

Theory teaching of human anatomy in Sports Physiology cannot be separated from a significant amount of time spent on picture hanging and blackboard-writing. Teachers are busy with blackboard-writing and frequent change of pictures, while students are busy taking down notes, resulting in the waste of a significant amount of time. Students have no time to actively think, let alone understand and remember. Touch screen multimedia teaching technology can simplify blackboard-writing and picture hanging for teachers to have sufficient time to explain difficult points and key points. The pictures are highdefinition and interesting. Touch screen multimedia teaching technology can generally achieve the visual sense requirements for students in theory course teaching and reserve thinking space for students. Therefore, the teaching effect of touch screen multimedia teaching technology is significantly superior to traditional teaching mode.

\section{CONCLUSIONS}

To some extent, touch screen multimedia teaching technology can make up for the shortcomings of traditional teaching and boost student learning interest along with teaching quality. However, touch screen multimedia teaching software also has certain limitations. For example, in the experimental course, the software can only display experimental operation steps to students but could not replace manual operation. Hence, both the touch screen multimedia teaching mode and traditional teaching mode need to be properly combined. For knowledge points that students find difficult to understand, touch screen multimedia teaching may be used, whereas traditional teaching should be utilized for those points that require manual operation and face-to-face exchange.

\section{REFERENCES}

[1] Walsh J.P., Sun J.C.Y., \& Riconscente M., "Online teaching tool simplifies faculty use of multimedia and improves student interest and knowledge in science," CBE-Life Sciences Education, vol. 10, no. 3, pp. 298-308, June 2011. http://dx.doi.org/10.1187/cbe.1103-0031

[2] Zhou X.Y., Cao H., "Study on application of multimedia CAI technology in sports teaching," Journal of Beijing Sport University, vol. 23, no. 2, pp. 245-246, February 2000.

[3] Zhou Y., "Design and implementation of intelligent long-distance multimedia sports teaching system," Sports Science, vol. 22, no. 1, pp.51-53, January 2002,

[4] Zhao P.Y., Ji L.W., Li S.B., Dong Y., Feng G., "Practice research on share-based sports multimedia teaching system - study on collaborative learning in computer-supported PE course," Modern Educational Technology, vol. 20, no. 2, pp.146-149, February 2010 .

[5] Jain A., Bhargava D.B., Rajput A., "TOUCH-SCREEN TECHNOLOGY," International Journal of Advanced Research in Computer Science and Electronics Engineering (IJARCSEE), vol. 2, no. 1, pp. 74-78, January 2013.

[6] Klatzky R.L., Giudice N.A., Bennett C.R., Loomis J.M., "Touchscreen technology for the dynamic display of 2D spatial information without vision: Promise and progress," Multisensory research, vol. 27, no. 5-6, pp. 359-378, June 2014. http://dx.doi.org/10.1163/22134808-00002447

[7] Islam M.A., Haque A.K.M.F., Ali M.S., Ahmed M., "Design and development of a cost effective laser ray touch screen technology," Bangladesh Electronic Society, vol. 11, no. 1-2, pp.51-56, February 2011.

[8] Kim H., Chacko P., Zhao J., Montclare J.K., "Using Touch-Screen Technology, Apps, and Blogs To Engage and Sustain High School Students' Interest in Chemistry Topics," Journal of Chemical Education, vol. 91, no. 11, pp.1818-1822, November 2014. http://dx.doi.org/10.1021/ed500234z

[9] Li L.Z., "Color ergonomics and color design of human-computer interface," Human Ergonomics, vol. 10, no. 3, pp.54-57, March 2004.

\section{AUTHORS}

Ziyi YU is an associate professor in Department of Physical Education, Hubei University of Automotive Technology, Shiyan, 442002, China. His research interests include Physical Education and Sports Exercise. (yuziyi76@yeah.net)

Submitted 14 October 2015. Published as resubmitted by the author 26 December 2015. 